\title{
Onychomycosis and Onychomatricoma
}

\author{
Penelope Kallis Antonella Tosti \\ Department of Dermatology and Cutaneous Surgery, University of Miami Miller School of Medicine, \\ Miami, Fla., USA
}

\section{Established Facts}

- Onychomycosis is among one of the most common nail disorders.

- Onychomatricoma is a rare benign tumor of the nail matrix.

\section{Novel Insights}

- We describe the association between these two nail disorders and their combined dermoscopic features.

\section{Key Words}

Onychomycosis · Onychomatricoma $\cdot$ Nail disorders

\begin{abstract}
Nail dermoscopy is helpful in the differential diagnosis of nail disorders including onychomycosis and pigmented and nonpigmented nail tumors. We report two cases of onychomatricoma with concurrent onychomycosis of the same digit. In both cases, dermoscopy of the nail plate exhibited features of onychomatricoma, whereas dermoscopy of the distal free edge revealed features of onychomycosis. It is not uncommon for patients with onychomatricoma to develop coexisting onychomycosis, as channels created by the tumor render the nail plate susceptible to invasion by fungi.
\end{abstract}

(c) 2016 S. Karger AG, Basel

\section{Introduction}

Onychomatricoma is an uncommon benign tumor of the nail matrix characterized clinically by thickening of the affected nail plate with longitudinal yellow discoloration, transverse overcurvature, and splinter hemorrhages [1]. Tumor projections into the nail plate produce honeycomb-like cavities that are visible at frontal view of the nail plate free margin [2]. Onychomatricoma can occur in association with onychomycosis, and there are reported cases where the nail abnormalities were misdiagnosed and treated as onychomycosis, a much more common fungal infection of the nail [3]. Here, we report two cases of onychomatricoma with concomitant onychomycosis, emphasizing how dermoscopic features can suggest these two entities in combination.

\section{KARGER 125}

E-Mail karger@karger.com www.karger.com/sad
(C) 2016 S. Karger AG, Basel

2296-9195/16/0014-0209\$39.50/0
Penelope Kallis, BS, BA

University of Miami Miller School of Medicine

1111 SW 1st Avenue, Apt 1919

Miami, FL 33130 (USA)

E-Mail pkallis@med.miami.edu 
Fig. 1. a A brown discolored nail plate. b Frontal view revealing a thickened nail plate. c Nail plate dermoscopy showing homogenous brown discoloration with proximal splinter hemorrhages. d Nail dermoscopy of the distal free edge revealing subungual hyperkeratosis with a 'ruin appearance'.
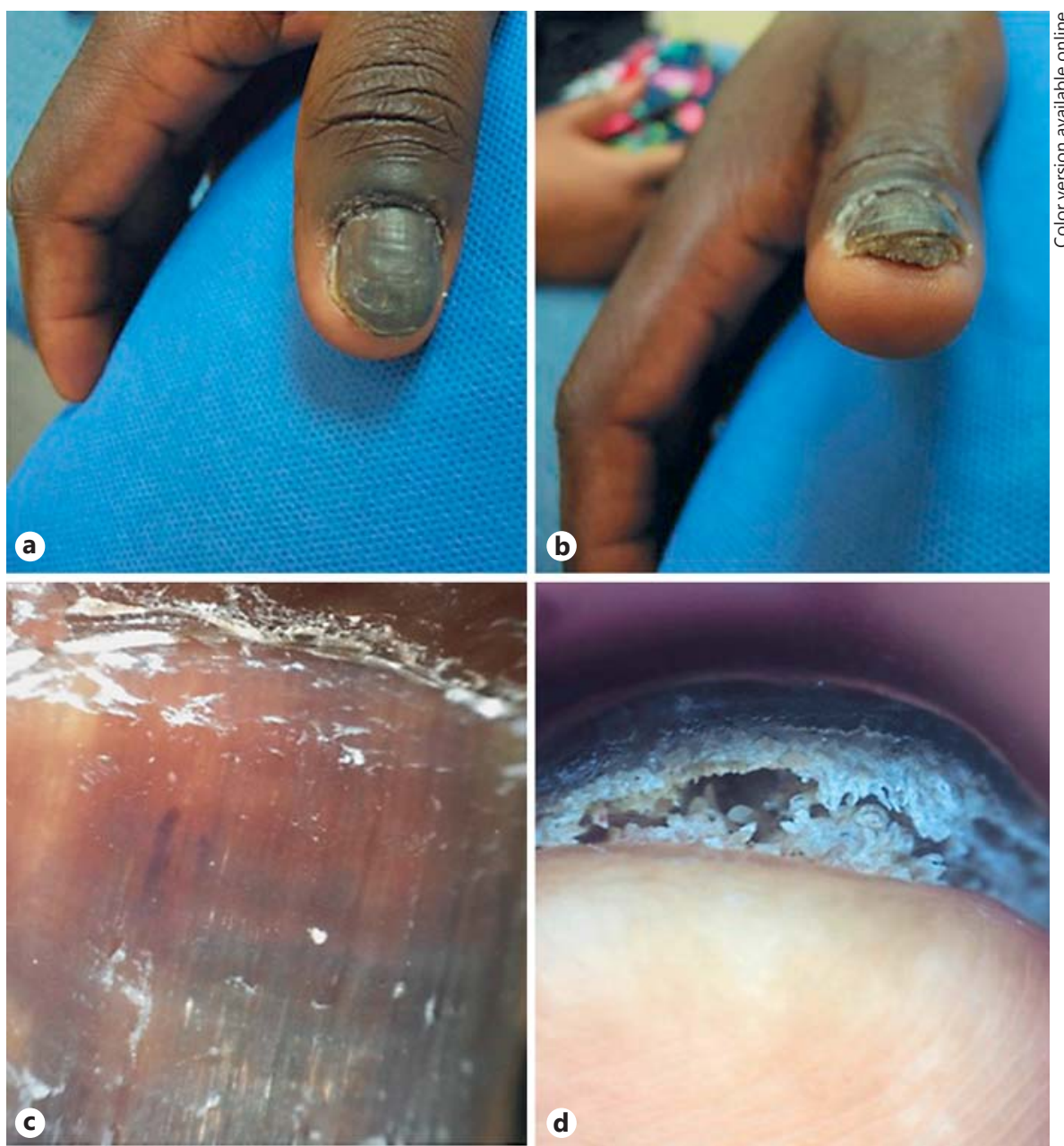

\section{Case Report}

\section{Case 1}

A 35-year-old African-American man presented with a thickened and pigmented right thumbnail. He had a diagnosis of onychomycosis confirmed by a positive nail clipping and has been treated with oral terbinafine for 2 months without improvement. Clinical examination revealed a thickened pigmented nail with increased overcurvature and subungual hyperkeratosis (fig. 1a, b). Nail plate dermoscopy revealed homogenous, brown discoloration of the nail plate with proximal splinter hemorrhages (fig. 1c). Dermoscopy of the distal free edge showed subungual hyperkeratosis with a 'ruin appearance' (fig. 1d). The nail plate was avulsed, exposing a tumor emerging from the nail matrix. Histological examination confirmed the diagnosis of onychomatricoma in a nail with onychomycosis.

\section{Case 2}

A 47-year-old man presented with a 2-year history of onychomycosis of his left great toenail that had been unsuccessfully treated with topical antifungals. The left great toenail exhibited longitudinal yellow discoloration, thickening, and overcurvature, most pronounced on the lateral third (fig. 2a, b). Dermoscopic examination of the nail plate revealed longitudinal white lines (fig. 2c), and dermoscopy of the free edge displayed a 'ruin appearance' of subungual keratosis (fig. 2d). The nail plate was removed and a tumor appearing from the nail matrix was surgically excised. Pathology confirmed the diagnosis of onychomatricoma and onychomycosis.

\section{Discussion}

Onychomatricoma is a filamentous tufted tumor localized in the nail matrix that was first described by Baran and Kint in 1992 [1]. The tumor extends finger-like projections of nail matrix epithelium into the attached nail plate, and the resultant nail plate alteration manifests classically as yellow discoloration, longitudinal ridging, and funnel-shape deformity $[1,4]$. Nail dermoscopy is a helpful tool in the evaluation for onychomatricoma and may reveal longitudinal, parallel white lines, splinter 

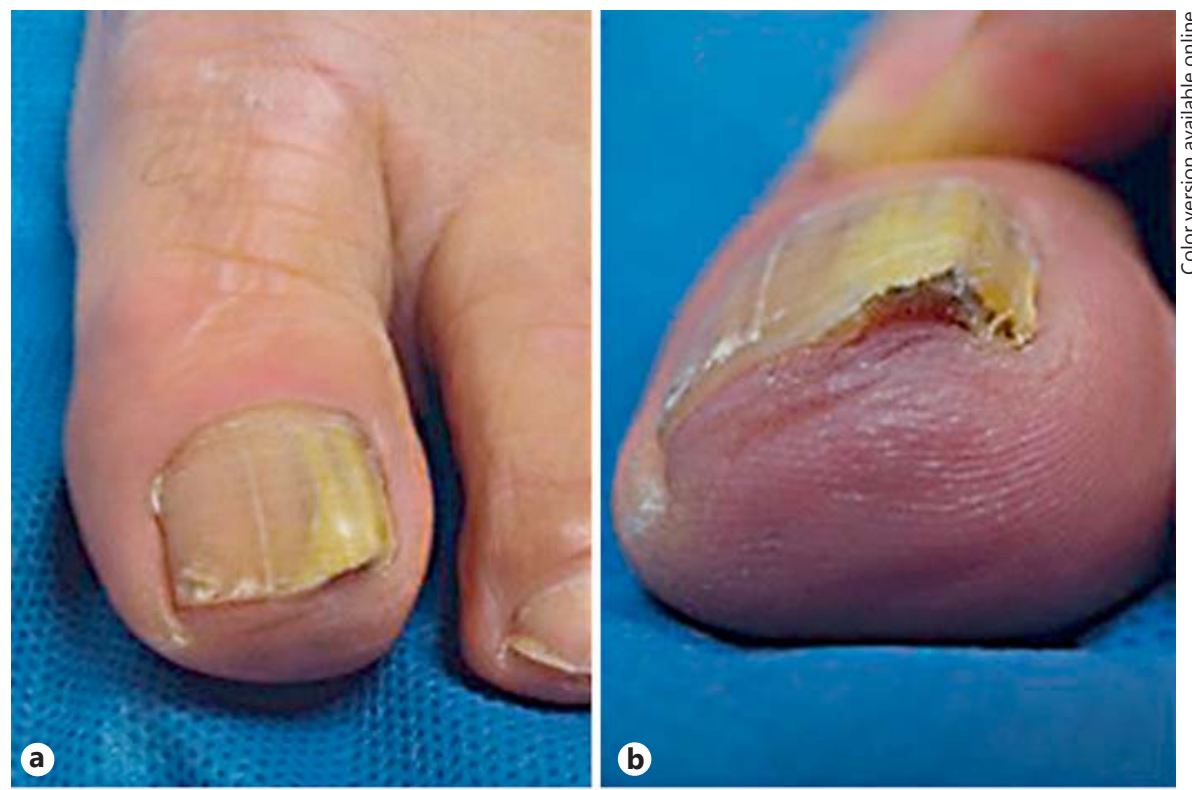

Fig. 2. a Yellow discoloration of the lateral third of the nail plate. b Frontal view revealing yellow discoloration and thickening at the lateral edge of the nail plate. $\mathbf{c}$ Nail plate dermoscopy exhibiting longitudinal white lines. $\mathbf{d}$ Dermoscopy of the distal free edge of the nail plate yielding subungual hyperkeratosis with 'ruin appearance'.
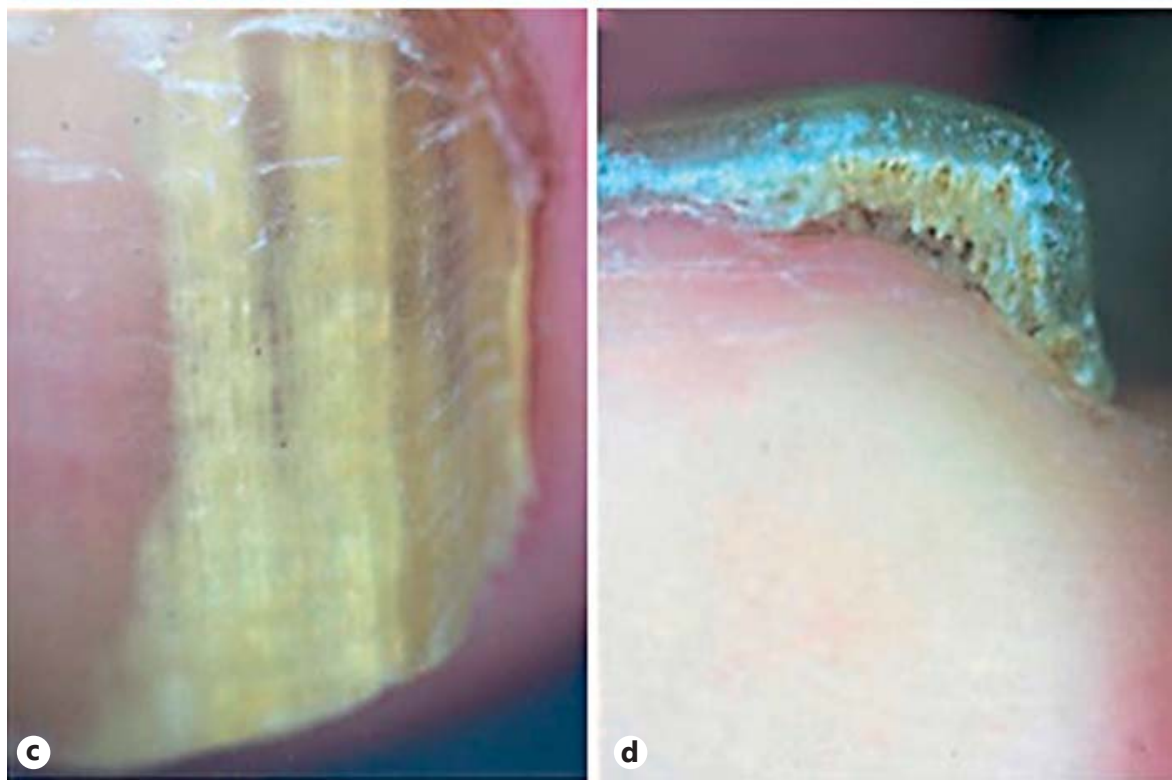

Table 1. Cases of onychomatricoma initially diagnosed as onychomycosis

\begin{tabular}{lll}
\hline First author, year & Cases, $\mathrm{n}$ & Misdiagnosed cases, $\mathrm{n}$ \\
\hline Haneke [6], 1995 & 1 & 1 \\
Van Holder [7], 1999 & 1 & 1 \\
Estrada-Chavez [8], 2007 & 2 & 1 \\
Khelifa [9], 2008 & 1 & 1 \\
Soto [10], 2009 & 3 & 3 \\
Durrant [11], 2012 & 1 & 1 \\
Fernández-Sánchez [12], 2012 & 2 & 1 \\
Ozüturk Durmaz [13], 2013 & 1 & 1 \\
Poojary [14], 2015 & 1 & 1 \\
Graves [15], 2015 & 1 & 1 \\
\hline
\end{tabular}


hemorrhages, and woodworm-like cavities at the distal free edge, corresponding to nail plate channels produced by tumor extension [5]. Finally, avulsion of the nail exposes a funnel-shaped tumor emanating from the nail matrix [1].

In several reported cases, onychomatricoma was initially diagnosed and unsuccessfully treated as a fungal infection of the nail (table 1). Onychomycosis is the most prevalent nail disease, accounting for $50 \%$ of all nail disorders [16]. Dermoscopy is useful in the diagnosis of onychomycosis with two characteristic findings described at nail plate and free edge dermoscopy. Nail plate dermoscopy reveals a jagged edge appearance of the proximal margin of the onycholytic area with spikes directed to the proximal nail fold, and overall irregular pigmentation in longitudinal striae of different colors, giving an appearance similar to the aurora borealis [17]. Dermoscopy, of the frontal margin of the affected nail plate shows a 'ruin appearance' of the subungual hyperkeratosis [18].

Though onychomatricoma may be misdiagnosed as the more common onychomycosis, it is not uncommon for the two nail disorders to coexist. We report two cases of onychomatricoma in concurrence with onychomycosis; a combination that has been previously reported in four cases, one of which in a child $[3,4]$. Pre-existing nail dystrophy is a known risk factor for the development of onychomycosis [19]. Thus, it should be no surprise that onychomatricoma may be a predisposing factor for onychomycosis, as the channels within the nail plate created in onychomatricoma provide a favorable environment for fungal invasion.

In our two cases, dermoscopy shows a combination of the dermoscopic findings typical of these two nail disorders. In particular, the nail plate dermoscopy of both cases had features described in onychomatricoma, with the pathognomonic longitudinal white lines and splinter hemorrhages. Dermoscopy of the frontal margin of the nail plate showed 'ruin appearance' described in onychomycosis instead of the typical honeycomb cavities typical of onychomatricoma.

Our cases confirm the association between onychomycosis and onychomatricoma and show how dermoscopy can help in differentiating onychomatricoma, onychomycosis, or the two in combination.

\section{Statement of Ethics}

All subjects have given informed consent to publish the details of their case.

\section{Disclosure Statement}

The authors have no conflicts of interest to disclose.

\section{References}

1 Baran R, Kint A: Onychomatrixoma: filamentous tufted tumour in the matrix of a funnelshaped nail: a new entity (report of three cases). Br J Dermatol 1992;126:510-515.

2 Miteva M, de Farias DC, Zaiac M, Romanelli P, Tosti A: Nail clipping diagnosis of onychomatricoma. Arch Derma2011;147:11171118.

3 Fayol J, Baran R, Perrin C, Labrousse F: Onychomatricoma with misleading features. Acta Derm Venereol 2000;80:370-372.

4 Piraccini BM, Antonucci A, Rech G, Starace M, Misciali C, Tosti A: Onychomatricoma: first description in a child. Pediatr Dermatol 2007;24:46-48.

5 Lesort C, Debarbieux S, Duru G, Dalle S, Poulhalon N, Thomas L: Dermoscopic features of onychomatricoma: a study of 34 cases. Dermatology 2015;231:177-183.

6 Haneke E, Fränken J: Onychomatricoma. Dermatol Surg 1995;21:984-987.

7 Van Holder C, Dumontier C, Abimelec P: Onychomatricoma. J Hand Surg Br 1999;24: $120-121$.
8 Estrada-Chavez G, Vega-Memije ME, Toussaint-Caire S, Rangel L, Dominguez-Cherit J: Giant onychomatricoma: report of two cases with rare clinical presentation. Int J Dermatol 2007;46:634-636.

9 Khelifa E, Tschanz C, Masouyé I, Kerl K, Borradori L: A rare tumour of the nail apparatus: onychomatricoma. J Eur Acad Dermatol Venereol 2008;22:1127-1128.

10 Soto R, Wortsman X, Corredoira Y: Onychomatricoma: clinical and sonographic findings. Arch Dermatol 2009;145:1461-1462.

11 Durrant MN, Palla BA, Binder SW: Onychomatricoma: a case report with literature review. Foot Ankle Spec 2012;5:41-44.

12 Fernández-Sánchez M, Saeb-Lima M, CharliJoseph Y, Mendez-Flores S, Sánchez-Hernández C, Carbajosa-Martinez J: Onychomatricoma: an infrequent nail tumor. Indian J Dermatol Venereol Leprol 2012;78:382-383.

13 Ozüturk Durmaz E, Sezer E, Dikicioğlu Çetin E, Sahin S: Onychomatricoma masquerading as candida onychomycosis and paronychia. Acta Derm Venereol Croat 2013;21:198-201.
14 Poojary SA, Halwai V: A tumor hidden beneath the nail plate: report of a rare case of onychomatricoma with three-dimensional histopathological analysis and immunohistochemical study. Indian J Dermatol 2015;60: 212.

15 Graves MS, Anderson JK, LeBlanc KG, Sheehan DJ: Utilization of Mohs micrographic surgery in a patient with onychomatricoma. Dermatol Surg 2015;41:753-755.

16 Faergemann J, Baran R: Epidemiology, clinical presentation and diagnosis of onychomycosis. Br J Dermatol 2003;149(suppl 65):1-4.

17 Piraccini BM, Balestri R, Starace M, Rech G: Nail digital dermoscopy (onychoscopy) in the diagnosis of onychomycosis. J Eur Acad Dermatol Venereol 2013;27:509-513.

18 De Crignis G, Valgas N, Rezende P, Leverone A, Nakamura R: Dermatoscopy of onychomycosis. Int J Dermatol 2014;53:e97-e99.

19 Tosti A, Hay R, Arenas-Guzman R: Patients at risk of onychomycosis - risk factor identification and active prevention. J Eur Acad Dermatol Venereol 2005;19(suppl 1):13-16. 